DOI: http://dx.doi.org/10.33846/hn40603

http://heanoti.com/index.php/hn

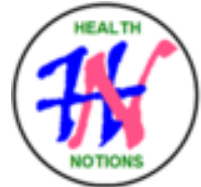

RESEARCH ARTICLE

URL of this article: http://heanoti.com/index.php/hn/article/view/hn40603

\title{
The Relationship Between Knowledge and Assessment of Pregnant Women with the Utilization of Dental Health Services
}

\author{
Aprilia Martha Bakoil ${ }^{1(\mathrm{CA})}$, Dinah Charlota Lerik ${ }^{2}$, Sabina Gero 3 \\ ${ }^{1(\mathrm{CA})}$ Postgraduate School of Public Health Science, Universitas Nusa Cendana, Indonesia; \\ marthabakoil733@gmail.com (Corresponding Author) \\ ${ }^{2}$ Postgraduate School of Public Health Science, Universitas Nusa Cendana, Indonesia; \\ mdinah.lerik@staf.undana.ac.id \\ ${ }^{3)}$ Department of Nursing, Poltekkes Kemenkes Kupang, Indonesia; sabina93r0@gmail.com
}

\begin{abstract}
Improving the optimal health status requires commitment and continuous effort so that a sub-standard development goals (SDGS) program is formed, one of which aims to tackle health problems in pregnant women. Dental and oral disease during pregnancy is a public health problem. The incidence of dental and oral diseases during this period is due to a lack of knowledge about oral health maintenance. The low use of service facilities by the community is related to treatment seeking behavior and ill-health concepts from the community. The purpose of the study was to analyze the relationship of knowledge and assessment of pregnant women with the use of dental health services at the Dental Clinic at the Health Centers in Kupang City. The design of this research was cross-sectional. The samples were 250 respondents, selected using proportional random sampling technique. Data were collected using a questionnaire as an instrument, then analyzed using ordinal regression test. Based on the data analysis results, it could be concluded that there was relationship between knowledge and assessment of pregnant women with the utilization of dental and oral health services in Public Health Center in Kupang City.
\end{abstract}

Keywords: knowledge; pregnant women; utilization; dental and oral health services

\section{INTRODUCTION}

\section{Background}

Improving the optimal health status requires commitment and continuous hard work to form a substantable development goals (SDGs) program, one of which aims to tackle health problems in pregnant women. the world health organization (WHO), estimates that around 711,000 to 948,148 Indonesian women and young women each year will experience a high risk of complications during pregnancy, childbirth and the puerperium $^{(1)}$.

Dental and oral health is one of the things that need to be considered during pregnancy, this is because pregnant women are one of the groups that are vulnerable to dental and oral diseases ${ }^{(2)}$. Dental and oral disease during pregnancy is an important public health problem throughout the world because of its prevalence and its association with daily life which can be detrimental to pregnancy, birth outcomes and caries in early childhood and chronic diseases ${ }^{(3)}$.

The incidence of dental and oral diseases during pregnancy is not merely influenced by the pregnancy itself but also because of a lack of knowledge of oral and dental health care so that it affects bad dental and oral health behaviors including the behavior of pregnant women visiting to check their dental health in health services. Mwaiswelo and Masalu's research (2006) shows that the lack of knowledge of pregnant women in maintaining oral health in which only $16 \%$ of pregnant women receive dental and oral health education, $97 \%$ brush their teeth, $52 \%$ of pregnant women believe that regular brushing will reduce risk of gum problems and only $3.7 \%$ of pregnant women visit the dentist during pregnancy ${ }^{(4)}$. The behavior of visits to the dentist is 
influenced by factors including personal, economic status and knowledge about the relationship of pregnancy with oral health ${ }^{(5)}$.

The low use of service facilities by the community is related to treatment seeking behavior and ill-health concepts from the community. The existence of facilities with various treatment systems opens opportunities for people to get treatment at promising facilities. Prihastari and Andreas's research (2015) found that barriers for pregnant women to visit the dentist most important came from within themselves as many as $73 \%$ (19 people) and the rest came from external factors (external) namely $27 \%$ ( 7 people). External barriers, among others, are due to high costs of $57 \%$ ( 4 people), prohibited by husbands $15 \%$ ( 1 person), prohibited relatives $14 \%$ ( 1 person), and due to working time $14 \%$ (1 person $)^{(6)}$.

\section{Purpose}

The purpose of the study was to analyze the relationship between knowledge and assessment of pregnant women with the utilization of dental health services at the Dental Clinic at the Health Centers in Kupang City.

\section{METHODS}

This type of research was a quantitative study using a cross-sectional design. The study population was all pregnant women in the working area of the Public Health Center of Kupang City. The sample size was 250 pregnant women, selected by proportional random sampling technique. Data was collected through filling out the questionnaire as an instrument. Then the data is processed through the stages of editing, coding and tabulating; then analyzed using logistic regression tests.

\section{RESULTS}

A summary of the results of data analysis is presented in table 1.

Table 1 . Summary of the logistic regression test results

\begin{tabular}{lcccc}
\hline \multicolumn{1}{c}{ Variables } & Estimate & Sig & $95 \%$ & CI \\
\hline Knowledge & & & Lower Bound & Upper Bound \\
\hline Assessment of pregnant women & -1.022 & 0.05 & -2.073 & 0.028 \\
\hline
\end{tabular}

Based on table 3 it can be interpreted that the utilization of dental health services was related to the level of knowledge of pregnant women $(p$-value $=0.05)$ and the assessment of pregnant women $(p$-value $=$ $0.02)$.

\section{DISCUSSION}

Based on the results, there was a relationship between knowledge and the utilization of dental and oral health services by pregnant women in health center. The level of knowledge of a person influences a lot of individual behavior, where the higher the level of knowledge of pregnant women about the benefits of dental and oral health services, the higher the level of awareness of pregnant women to visit the Public Health Center. A behavior that is based on knowledge, awareness and a positive attitude will be long-lasting, whereas if the behavior is not based on knowledge and awareness then the behavior is temporary. Knowledge that ultimately affects the attitude that determines pregnant women to take advantage of dental and oral health services. The results of this study are the same as the results of research conducted by Suarniti namely there is a meaningful relationship between knowledge and the utilization of dental and oral health services in Public Health Center ${ }^{(7)}$. Another study conducted by Byrappagari, et al. Stated that good oral health knowledge does not mean better utilization of dental services, but there are other obstacles to seeking treatment ${ }^{(8)}$.

Based on the results, there was a correlation between the assessment variables of pregnant women with the utilization of dental and oral health services at the Public Health Center. The need for health services for pregnant women is a fundamental factor in using health services in Puskesmas, the quality of health services and adequate care facilities will get a good assessment from pregnant women, so that pregnant women are satisfied with the services provided and are motivated to the Public Health Center to get dental health services and mouth $^{(9)}$. The results of this study are the same as the results of a study conducted by Napirah, et al who stated that there is a relationship between people's perceptions about health with the utilization of health services in the work area of Tambarana Health Center in Poso Pesisir Utara District Poso District ${ }^{(10)}$. 


\section{CONCLUSION}

There is a correlation between knowledge and assessment of pregnant women on the utilization of dental and oral health services in Public Health Center in Kupang City, meaning that good knowledge of pregnant women in the utilization of dental and oral health services at public health center can improve the degree of dental and oral health.

\section{REFERENCES}

1. Listi. Millenium Development Goals (MDG'S) Achievements Relating to the Health of Children and Mothers. Online Journal of the Faculty of Economics Students. 2015;2(2).

2. Muhsinah, Yuniarrahmah E, Sukmana BI. Effects of Dental and Oral Hygiene with Gingivitis Status in Pregnant Women in 2012. Dentino. 2014;2(2):110-114.

3. Suwargiani AA, Personal SMI, Hidayat W, Wardani R, Jasrin TA, Zubaedah A. Caries and Periodontal Health Experiences and Care Needs Pregnant mother. Journal of Dentistry. 2018;30(1):20-25.

4. Mwaiswelo RO, Masalu JR. Oral Health Knowledge and Behavior among Pregnant Women in Keyla District, Mabeya, Tanzania. Tanzania Dental Journal. 2007;14(2):47-52.

5. Anggraini R, Andreas P. Oral Dental Health and Utilization of Oral Dental Health Services in Pregnant Women. Dentistry Magazine. 2015;1(2):193-200.

6. Prihastari A, Andreas P. Behavioral Antasedent Factors that Influence Utilization of Dental Health Services for Pregnant Women. Indonesian Dentistry Magazine. 2015;1(2):208-215.

7. Suarniti LP. The Effect of Knowledge of Pregnant Women on the Utilization of Dental and Oral Health Services. Journal of Dental Health. 2014;2(1).

8. Byrappagari D, Kemink MK, Ray JJ. Oral Health Conference and The Utilization of Dental Services: A Survey of Urban Native Americans. Journal of Dental Oral Health. 2017;3(2):063.

9. Darma A, Hidayati, Oensil F. Differences Between Dental Health Service Quality and Utilization of Community Health Centers in the Padang Based on Indicators of Utilization Effectiveness. Padjajaran Journal of Dentistry. 2018;30(2).

10. Napirah MR, Rahman A, Tony A. Factors Related to the Utilization of Health Services in the Work Area of the Health Center. Journal of Urban Development. 2016;4(2):29-39. 